\title{
Multi-channel support and ticketing interface for online support management system platforms
}

\author{
Roger S. Mission* \\ College of Computer Studies, University of Antique Antique, Philippines
}

\begin{abstract}
This paper discussed the development of multi-channel support and ticketing interface for online support management system (OSMS) platforms that streamline the entire support requests and convert the stakeholder's queries coming from multiple channels to provide a holistic view of all ticket-related information in one place. The system increases organization efficiency, allowing the technical support agents to track, prioritize, and resolve support queries within a single interface. The researcher anchors the study on research and development $(\mathrm{R} \& \mathrm{D})$ which aims to understand a subject matter more completely and build on the body of knowledge relating to it. The data collection technique used was unstructured interviews, document analysis, and modified surveyquestionnaire adapted from ISO/IEC 25010 software product quality models had been used for system evaluation. The results showed that the respondents were satisfied with the features and capabilities of the developed system and complied with the specifications based on ISO/IEC 25010 software product quality standards.
\end{abstract}

Keywords: Multi-channel support, Helpdesk, Online support management system.

\section{OPEN ACCESS}

Received: February 2, 2021

Revised: April 12, 2021

Accepted: May 11, 2021

Corresponding Author:

Roger S. Mission

$\underline{\text { rsmission@antiquespride.edu.ph }}$

Copyright: The Author(s).

This is an open access article distributed under the terms of the Creative Commons Attribution License (CC BY 4.0), which permits unrestricted distribution provided the original author and source are cited.

Publisher:

Chaoyang University of

Technology

ISSN: $1727-2394$ (Print)

ISSN: $1727-7841$ (Online)

\section{INTRODUCTION}

Information technology (IT) plays a significant role in all aspects of digital society and challenges the educational system. The increasing role played by information technology changed how we communicated with each other and how we find needed information in our work and daily lives.

Customer service is an important competitive lever for the modern firm. At the same time, the continuous evolution and performance improvements in information technology capabilities have enabled the utilization of multichannel service delivery strategies (Lui and Piccoli, 2016).

The multi-channel support and ticketing interface for OSMS platforms is one of the core parts for acceptable service and operation. Gallimore (2020) defines "multi-channel support as a combination of two or more channels that companies use to communicate with their end-users." Ozdoruk (2020), also states that "in order to meet customer expectations, companies must provide multi-channel support service" to make customers happy by making them feel appreciated and listened to. Essentially, multi-channel support opens the door for numerous choices to make it convenient for stakeholders to send their feedback or complaints. The goal of multi-channel integration provides a superior customer experience that is consistent and seamless across channels (Goersch, 2002) to deliver fast, reliable internal customer service, resulting in improved IT department operations and satisfied employees (Ismaili et al., 2018). The ability to integrate innovative technology into viable learning strategies is beneficial and promising. Stone et al. (2002) enumerate the benefits of the multi-channel support from identification and capture of opportunities for increasing value per customer, increased convenience and improve the experience, increased efficiency through the sharing of processes, technology and information, organizational flexibility, exploiting customer data to identify customer needs indicating new paths for growth, and the ability to switch 


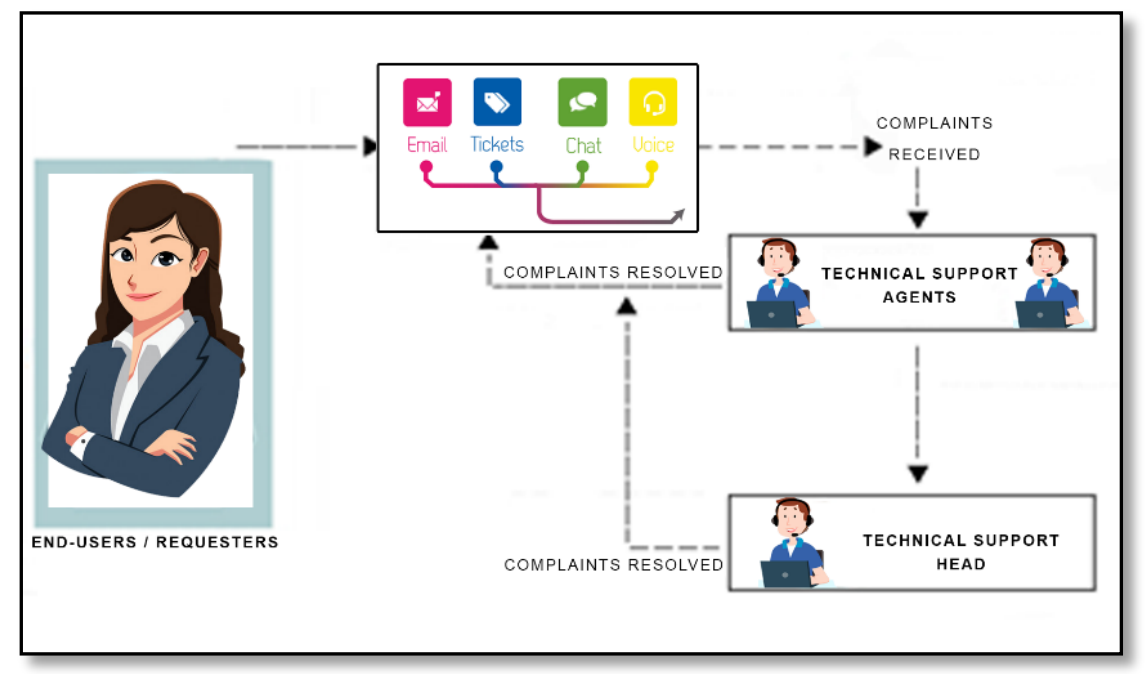

Fig. 1. Conceptual diagram

easily between the various channels, when it suits them and wherever they want to depend on their preference and the type of interaction. From a wider perspective, it is the main part of the service function which collects all the queries from all possible channels in one place (Mission, 2020).

In universities, support for business-related requests by every department is of prime consideration, especially since these requests concern immediate disposal of duties to serve stakeholders. When these support services are hampered, the quality of service of the institution will decline. Since the institution provides services to thousands of stakeholders, it is fitting to have a multi-channel support and ticketing interface that streamline the entire support requests and converts the stakeholder's queries coming from multiple channels to provide a holistic view of all ticketrelated information in one place (Mission, 2020).

Currently, most institutions relied on a single channel approach to connect and interact with stakeholders. Through this system, it helps collects all support tickets from different channels and organizes them in one tab. Thus, information gathered as a result of monitoring the processes and transactions of the system can help in planning the future of the institution in establishing a good information technology infrastructure.

The major concept of this study focuses on the development and evaluation of the multi-channel support and ticketing interface for OSMS platforms at the universities.

Fig. 1 shows the conceptual diagram of how the multichannel support and ticketing interface for OSMS platforms works. The diagram shows the stakeholders will create a complaint via the available primary channel. A technical support agent receives a complaint created then verifies that the problem is real, and not just perceived. The technical support agent will also ensure that enough information about the problem is obtained from the stakeholder. This information generally includes the environment of the stakeholder, how and when the issue occurs, and all other relevant circumstances. The technical support agent creates the issue in the system, entering all relevant data, as provided by the requester.

As work is done on that issue, the system is updated with new data by the technical support agent. Any attempt at fixing the problem should be noted in the system. The ticket status most likely will be changed from open to pending. After the issue has been fully addressed, it is marked as resolved in the system.

Escalation of the request is done if in case a technical support agent cannot - for whatever reason - handle the service request, in this case, the head of the technical support team will resolve the issues.

This study aims to develop a multi-channel support and ticketing interface for OSMS platforms that streamline the entire support requests and converts the stakeholder's queries coming from multiple channels to provide a holistic view of all ticket-related information in one place for universities. Specifically, it seeks to answer the following questions: What are the steps undertaken in the development of the system? What is the difference in the evaluation of the IT instructor, technical support agent \& office personnel based on ISO/IEC 25010 software product quality in terms of the following: functional suitability, performance efficiency, compatibility, usability, reliability, security, and maintainability? What is the difference in the evaluation of the developed system among the three groups of respondents? And what are the problems encountered by the respondents during system testing from the perspective of the IT instructor, technical support agent, and office personnel? 


\section{MATERIALS AND METHODS}

\subsection{Participants}

For the initial deployment and testing, the study was conducted at the University of Antique, a state university in Antique founded in the year 1954 and offers courses across various disciplines such as technology, maritime studies, teacher education, computer studies, engineering, architecture, business, and arts and sciences. A total of 65 respondents were included in the study, divided into three groups who are chosen purposively: they are composed of 20 IT instructors, 38 office personnel, and six (6) technical support agents.

\subsection{Instrument and Measures}

The researcher anchors the study on research and development (R\&D) which aims to understand a subject matter more completely and build on the body of knowledge relating to it. The researcher also used the descriptive type of research on the conduct of the study. This method of research involves either identifying the characteristics of an observed phenomenon or exploring possible correlations among two or more phenomena.

The research instruments that were used are unstructured interviews, document analysis, and modified surveyquestionnaire adapted from ISO/IEC 25010 software product quality models had been used for system evaluation (European standards, 2011). ISO/IEC 25010 software product quality models provide the leading models for assessing software products which define a product quality model composed of eight characteristics (which are further subdivided into sub-characteristics) that relate to static properties of software. The model is applicable to both computer systems and software products. The characteristics and sub-characteristics provide consistent terminology for specifying, measuring, and evaluating system and software product quality. They also provide a set of quality characteristics against which stated quality requirements can be compared for completeness.
The frequencies and percentages were employed for each of the items that were categorized and presented in tables with data and results treated using statistical measures:

1. Weighted arithmetic mean was used to weigh the respondent's answer to determine the acceptability of the developed system. The researcher used the fivelevel Likert scale to determine the corresponding descriptive interpretation and was quantified using the scale ranging from "Highly Acceptable" to "Highly Unacceptable". For these analyses, in interpreting the weighted mean, the following scale was used: 4.515.00 (Highly Acceptable), 3.51-4.50 (Acceptable), 2.51-3.50 (Moderately Acceptable), 1.51-2.50 (Unacceptable), and 1.50 and below (Highly Unacceptable).

2. F-Test or One-Way analysis of variance (ANOVA) was used to determine if there are significant differences in the evaluation of the three respondents on evaluating the developed multi-channel support and ticketing interface for online support management system platforms.

The data that was gathered from the answered questionnaires were checked, classified, tabulated, and analyzed according to the research design described in using IBM statistical package for the social science (SPSS).

\section{RESULTS AND DISCUSSION}

\subsection{Development of the Multi-Channel Support and \\ Ticketing Interface for OSMS Platforms}

The software development life cycle (SDLC) stages undertaken in the development of the multi-channel support and ticketing interface for OSMS platforms for universities or institutions are presented in Fig. 2. The stages include Conceptualization, Technical feasibility, Development, Pilot testing, Creation of user's manual, and System evaluation.

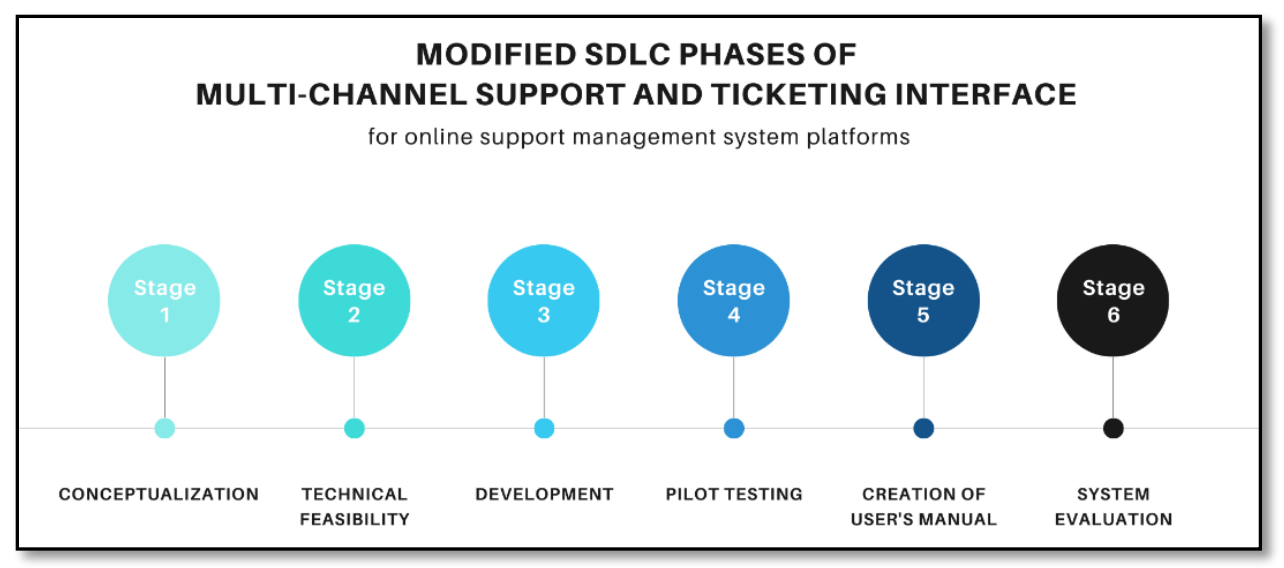

Fig. 2. SDLC phases of multi-channel support and ticketing interface for OSMS platforms 


\section{International Journal of Applied Science and Engineering}

Mission et al., International Journal of Applied Science and Engineering, 18(4), 2021044

Table 1. Evaluation of respondents in terms of functional suitability

\begin{tabular}{|c|c|c|c|c|c|c|}
\hline \multirow{2}{*}{$\begin{array}{l}\text { Functional suitability } \\
\text { sub-characteristics }\end{array}$} & \multicolumn{2}{|c|}{ Technical support agents } & \multicolumn{2}{|c|}{ IT instructors } & \multicolumn{2}{|c|}{ Office personnel } \\
\hline & Mean & Interpretation & Mean & Interpretation & Mean & Interpretation \\
\hline Functional completeness & 4.50 & Acceptable & 4.30 & Acceptable & 4.54 & $\begin{array}{c}\text { Highly } \\
\text { Acceptable }\end{array}$ \\
\hline Functional correctness & 4.67 & $\begin{array}{l}\text { Highly } \\
\text { Acceptable }\end{array}$ & 4.50 & Acceptable & 4.62 & $\begin{array}{l}\text { Highly } \\
\text { Acceptable }\end{array}$ \\
\hline $\begin{array}{c}\text { Functional } \\
\text { appropriateness }\end{array}$ & 4.17 & Acceptable & 4.10 & Acceptable & 4.54 & $\begin{array}{c}\text { Highly } \\
\text { Acceptable }\end{array}$ \\
\hline Total & 4.44 & Acceptable & 4.30 & Acceptable & 4.56 & $\begin{array}{c}\text { Highly } \\
\text { Acceptable }\end{array}$ \\
\hline
\end{tabular}

Table 2. Evaluation of respondents in terms of performance efficiency

\begin{tabular}{ccccccc}
\hline \multirow{2}{*}{$\begin{array}{c}\text { Performance efficiency } \\
\text { sub-characteristics }\end{array}$} & \multicolumn{2}{c}{ Technical support agents } & \multicolumn{2}{c}{ IT instructors } & \multicolumn{2}{c}{ Office personnel } \\
\cline { 2 - 7 } & Mean & Interpretation & Mean & Interpretation & Mean & Interpretation \\
\hline Time behavior & 4.17 & Acceptable & 3.95 & Acceptable & 4.51 & $\begin{array}{c}\text { Highly } \\
\text { Acceptable } \\
\text { Resource utilization }\end{array}$ \\
Capacity & 4.33 & Acceptable & 4.05 & Acceptable & 4.28 & Acceptable \\
Total & 3.67 & Acceptable & 3.80 & Acceptable & 4.00 & Acceptable \\
\hline
\end{tabular}

Stage 1: Shows the conceptualization of the multichannel support and ticketing interface for online support management system platforms. The developer identifies the problems, gathered all the information needed to develop the system, and understands the customer requirements and expectations of the product. The developer conducted an interview with the management information system director and investigated the school's present IT infrastructure. In this stage, after all the information and business requirements are gathered, the developer then defined the functional requirements of the system.

Stage 2: Technical feasibility, the study is technically feasible since there will not be much difficulty in getting the required resources for the development and maintaining the system as well.

Stage 3: Development stage, with the input from the system design the developer developed the user interface. Actual coding and customization of open-source software happen here as PHP (hypertext preprocessor) as a front end and MySQL as the back end of the system.

Stage 4: Pilot testing. After the development phase is done, the software program testing begins. The researcher set up and installed the multi-channel support and ticketing interface for online support management system platforms at the University of Antique.

Stage 5: Creation of user's manual, the researcher decided to print screen every detail of the system and created a step-by-step process, and give it to the person assigned for the operation for ease of use.

Stage 6: Evaluation of multi-channel support and ticketing interface for online support management system platforms to the IT instructors, office personnel, and technical support agents.

\subsection{Evaluation by IT Instructors, Technical Support} Agents and Office Personnel

Table 1 shows, both technical support agent and IT instructor evaluated the system as "Acceptable" with total mean scores of 4.44 and 4.30, respectively. While the office personnel evaluated the systems as "Highly Acceptable" with a mean score of 4.56 .

This result implies that as perceived by IT users the system can be integrated and is compatible with the existing programs that they are using. This result is more evident to the office personnel than to the technical support agent and IT instructor. This also suggests that the system possesses a relevant standard and work for which it was intended.

Table 2 shows the performance efficiency where IT instructors, technical support agents, and office personnel evaluated the systems as "Acceptable" with the mean scores of 4.05, 3.93, and 4.26, respectively. This means that the respondents are satisfied with what the system can do in a specified condition.

The performance efficiency factor describes the ability of a software product or system in managing the given amount of resources to provide and maximize performance (Kanellopoulos et al., 2010). This quality factor has also been decomposed into three lower factors including time behavior, resource utilization, and capacity (Haoues et al., 2017). Performance efficiency has been adapted into the system quality model to assess its capability to exhibit the required performance with regards to the number of resources needed to satisfy the needs of the users in a specified context of use (Mission, 2020). 


\section{International Journal of Applied Science and Engineering}

Mission et al., International Journal of Applied Science and Engineering, 18(4), 2021044

Table 3. Evaluation of respondents in terms of compatibility

\begin{tabular}{ccccccc}
\hline $\begin{array}{c}\text { Compatibility } \\
\text { sub-characteristics }\end{array}$ & \multicolumn{2}{c}{ Technical support agents } & \multicolumn{2}{c}{ IT instructors } & \multicolumn{2}{c}{ Office personnel } \\
\cline { 2 - 7 } Co-existence & 4.67 & $\begin{array}{c}\text { Highly } \\
\text { Acceptable }\end{array}$ & 3.95 & Acceptable & 4.41 & Acceptable \\
\hline Total & 4.67 & $\begin{array}{c}\text { Highly } \\
\text { Acceptable }\end{array}$ & 3.95 & Acceptable & 4.41 & Acceptable \\
\hline
\end{tabular}

Table 4. Evaluation of respondents in terms of usability

\begin{tabular}{|c|c|c|c|c|c|c|}
\hline \multirow{2}{*}{$\begin{array}{c}\text { Usability } \\
\text { sub-characteristics }\end{array}$} & \multicolumn{2}{|c|}{ Technical support agents } & \multicolumn{2}{|c|}{ IT instructors } & \multicolumn{2}{|c|}{ Office personnel } \\
\hline & Mean & Interpretation & Mean & Interpretation & Mean & Interpretation \\
\hline Appropriateness & 4.83 & $\begin{array}{c}\text { Highly } \\
\text { Acceptable }\end{array}$ & 4.30 & Acceptable & 4.67 & $\begin{array}{c}\text { Highly } \\
\text { Acceptable }\end{array}$ \\
\hline Learnability & 4.67 & $\begin{array}{l}\text { Highly } \\
\text { Acceptable }\end{array}$ & 4.35 & Acceptable & 4.59 & $\begin{array}{l}\text { Highly } \\
\text { Acceptable }\end{array}$ \\
\hline Operability & 4.83 & $\begin{array}{l}\text { Highly } \\
\text { Acceptable }\end{array}$ & 4.35 & Acceptable & 4.59 & $\begin{array}{l}\text { Highly } \\
\text { Acceptable }\end{array}$ \\
\hline User error protection & 4.67 & $\begin{array}{c}\text { Highly } \\
\text { Acceptable }\end{array}$ & 4.05 & Acceptable & 4.44 & Acceptable \\
\hline User interface aesthetics & 4.33 & Acceptable & 4.10 & Acceptable & 4.62 & $\begin{array}{c}\text { Highly } \\
\text { Acceptable }\end{array}$ \\
\hline Accessibility & 4.50 & Acceptable & 4.20 & Acceptable & 4.51 & $\begin{array}{l}\text { Highly } \\
\text { Acceptable }\end{array}$ \\
\hline Total & 4.64 & $\begin{array}{c}\text { Highly } \\
\text { Acceptable }\end{array}$ & 4.23 & Acceptable & 4.57 & $\begin{array}{c}\text { Highly } \\
\text { Acceptable }\end{array}$ \\
\hline
\end{tabular}

Table 5. Evaluation of respondents in terms of reliability

\begin{tabular}{ccccccc}
\hline Reliability & \multicolumn{2}{c}{ Technical support agents } & \multicolumn{2}{c}{ IT instructors } & \multicolumn{2}{c}{ Office personnel } \\
\cline { 2 - 7 } sub-characteristics & Mean & Interpretation & Mean & Interpretation & Mean & Interpretation \\
\hline Maturity & 4.33 & Acceptable & 4.30 & Acceptable & 4.46 & Acceptable \\
Availability & 4.50 & Acceptable & 4.25 & Acceptable & 4.41 & Acceptable \\
Fault tolerance & 4.17 & Acceptable & 4.10 & Acceptable & 4.23 & Acceptable \\
Recoverability & 4.00 & Acceptable & 3.95 & Acceptable & 4.59 & Highly \\
& 4.25 & Acceptable & 4.15 & Acceptable & 4.42 & Acceptable \\
\hline Total & & & & &
\end{tabular}

Table 3 shows the system's compatibility where technical support agents evaluated the systems as "Highly Acceptable" with a mean score of 4.67. On the other hand, both IT instructors and office personnel assess the system as "Acceptable" with their corresponding mean scores of 3.95 and 4.41 , respectively.

As evaluated by the respondents, the result implies that the system can perform its functions while sharing a common environment without interfering with other systems. This characteristic is clearly perceived by the IT technical support group compare to IT instructors and office personnel.

Peters and Aggrey (2020) added that compatibility is the capability of the software products or system to interact with other software products or systems without any glitches and performs its required functions while sharing the same hardware or software environments with other systems.
When the respondents evaluated the system's usability as seen in Table 4, it was revealed that both technical support agents and office personnel give a "Highly Acceptable" rating with mean scores of 4.64 and 4.57, respectively. Only the IT instructors give an "Acceptable" rating with a mean score of 4.23 .

These findings suggest that the system bears an effort need for use and easy to understand. In other words, the system is user-friendly. This is one of the important characteristics of a system. Nielsen (2012) added that "usability is a quality attribute that assesses how easy user interfaces are to use and it includes learnability, efficiency, and memorability."

Another characteristic that was evaluated was reliability as seen in Table 5. It was found out that the technical support agents, IT instructors, and office personnel give an "Acceptable" rating with their respective mean scores of $4.25,4.15$, and 4.42 . 


\section{International Journal of Applied Science and Engineering}

Mission et al., International Journal of Applied Science and Engineering, 18(4), 2021044

Table 6. Evaluation of respondents in terms of security

\begin{tabular}{|c|c|c|c|c|c|c|}
\hline \multirow{2}{*}{$\begin{array}{c}\text { Security } \\
\text { sub-characteristics }\end{array}$} & \multicolumn{2}{|c|}{ Technical support agents } & \multicolumn{2}{|c|}{ IT instructors } & \multicolumn{2}{|c|}{ Office personnel } \\
\hline & Mean & Interpretation & Mean & Interpretation & Mean & Interpretation \\
\hline Confidentiality & 4.83 & $\begin{array}{c}\text { Highly } \\
\text { Acceptable }\end{array}$ & 4.55 & $\begin{array}{c}\text { Highly } \\
\text { Acceptable }\end{array}$ & 4.54 & Highly Acceptable \\
\hline Integrity & 4.33 & Acceptable & 4.50 & Acceptable & 4.44 & Acceptable \\
\hline Non-repudiation & 4.00 & Acceptable & 4.10 & Acceptable & 4.33 & Acceptable \\
\hline Accountability & 4.17 & Acceptable & 4.30 & Acceptable & 4.41 & Acceptable \\
\hline Authenticity & 4.50 & Acceptable & 4.50 & Acceptable & 4.51 & Highly Acceptable \\
\hline Total & 4.37 & Acceptable & 4.39 & Acceptable & 4.45 & Acceptable \\
\hline
\end{tabular}

Table 7. Evaluation of respondents in terms of maintainability

\begin{tabular}{|c|c|c|c|c|c|c|}
\hline \multirow{2}{*}{$\begin{array}{c}\text { Maintainability } \\
\text { sub-characteristics }\end{array}$} & \multicolumn{2}{|c|}{ Technical support agents } & \multicolumn{2}{|c|}{ IT instructors } & \multicolumn{2}{|c|}{ Office personnel } \\
\hline & Mean & Interpretation & Mean & Interpretation & Mean & Interpretation \\
\hline Modularity & 4.17 & Acceptable & 4.20 & Acceptable & 4.67 & $\begin{array}{c}\text { Highly } \\
\text { Acceptable }\end{array}$ \\
\hline Reusability & 3.67 & Acceptable & 4.35 & Acceptable & 4.49 & Acceptable \\
\hline Analyzability & 4.17 & Acceptable & 4.15 & Acceptable & 4.69 & $\begin{array}{c}\text { Highly } \\
\text { Acceptable }\end{array}$ \\
\hline Modifiability & 4.17 & Acceptable & 4.35 & Acceptable & 4.41 & Acceptable \\
\hline Testability & 4.33 & Acceptable & 4.40 & Acceptable & 4.77 & $\begin{array}{c}\text { Highly } \\
\text { Acceptable }\end{array}$ \\
\hline Total & 4.10 & Acceptable & 4.29 & Acceptable & 4.60 & $\begin{array}{c}\text { Highly } \\
\text { Acceptable }\end{array}$ \\
\hline
\end{tabular}

This result supports that the system can maintain its level of performance under the specified conditions for a period of time. Pan (2019) defines software reliability as the probability of failure-free software operation for a specified period in a specified environment.

In terms of systems security, Table 6 revealed that technical support agents, IT instructors, and office personnel perceived that the system has an "Acceptable" rating. This is supported by their mean scores of 4.37, 4.39, and 4.45 , respectively.

It can be deduced that as perceived by the respondents, the system can prevent unauthorized access, whether accidental or deliberative.

According to Papazoglou et al. (2008), security is a grand challenge within service-oriented applications. Services must be developed to be self-protecting, which can anticipate, detect, identify, and protect against threats. In addition, Mission (2020) suggests that security testing is an indispensable and critical activity of the web application development life cycle which aims to maintain the confidentiality of the data, check against any information leakage, and maintain the functionality as intended.

As evaluated by the respondents shown in Table 7, the technical support agents and IT instructors give an "Acceptable" rating with their corresponding mean scores of 4.10, and 4.29, while office personnel gives a "Highly Acceptable" rating of 4.60 .

This result confirms that the system possesses analyzability for diagnosing inefficiencies, changeability for modifications, and testability for validating the modified software. Franca and Soares (2015) and Crouch (2019) added that the maintainability of software products or systems needs to be modified, corrected, or adapted to current changes in the environment without much difficulty.

Table 8 presents the overall result of the evaluation of IT instructors, technical support agents, and office personnel. It could be seen on the table that office personnel give a "Highly Acceptable" rating with a mean score of 4.50. While IT instructors and technical support agents give an "Acceptable" rating with an overall mean of 4.18 and 4.36 respectively.

The result implies that the newly developed system is more acceptable to the office personnel than IT instructors and technical support agents. This result could be attributed to the fact that IT instructors and technical support agents in general, are more knowledgeable in terms of system development than the office personnel.

The result shows that the system complied with the requirements or specifications based on ISO/IEC 25010 software product quality. 


\section{International Journal of Applied Science and Engineering}

Mission et al., International Journal of Applied Science and Engineering, 18(4), 2021044

Table 8. Overall result

\begin{tabular}{|c|c|c|c|c|c|c|}
\hline \multirow{2}{*}{$\begin{array}{l}\text { ISO/IEC } 25010 \text { software } \\
\text { product quality }\end{array}$} & \multicolumn{2}{|c|}{ Technical support agents } & \multicolumn{2}{|c|}{ IT instructors } & \multicolumn{2}{|c|}{ Office personnel } \\
\hline & Mean & Interpretation & Mean & Interpretation & Mean & Interpretation \\
\hline Functional Suitability & 4.44 & Acceptable & 4.30 & Acceptable & 4.56 & Highly Acceptable \\
\hline Performance Efficiency & 4.05 & Acceptable & 3.93 & Acceptable & 4.26 & Acceptable \\
\hline Compatibility & 4.67 & $\begin{array}{l}\text { Highly } \\
\text { Acceptable }\end{array}$ & 3.95 & Acceptable & 4.41 & Acceptable \\
\hline Usability & 4.64 & $\begin{array}{c}\text { Highly } \\
\text { Acceptable }\end{array}$ & 4.23 & Acceptable & 4.57 & Highly Acceptable \\
\hline Reliability & 4.25 & Acceptable & 4.15 & Acc & 4.42 & Acceptable \\
\hline Security & 4.37 & Acceptable & 4.39 & Acceptable & 4.45 & Acceptable \\
\hline Maintainability & 4.10 & Acceptable & 4.29 & Acceptable & 4.60 & Highly Acceptable \\
\hline Overall & 4.36 & Acceptable & 4.18 & Acceptable & 4.50 & Highly Acceptable \\
\hline
\end{tabular}

Table 9. ANOVA result on the difference in the evaluation made by the respondents

\begin{tabular}{cccccc}
\hline Source of variance & Sum of squares & $\mathrm{df}$ & Mean square & $\mathrm{F}$ & Sig. \\
\hline Between groups & .988 & 2 & .494 & $3.164 *$ & .049 \\
Within groups & 9.676 & 62 & .156 & & \\
Total & 10.664 & 64 & & & \\
\hline$* \mathrm{p}<0.05$ & & & & &
\end{tabular}

Table 10. Tukey HSD results as post hoc analysis for ANOVA

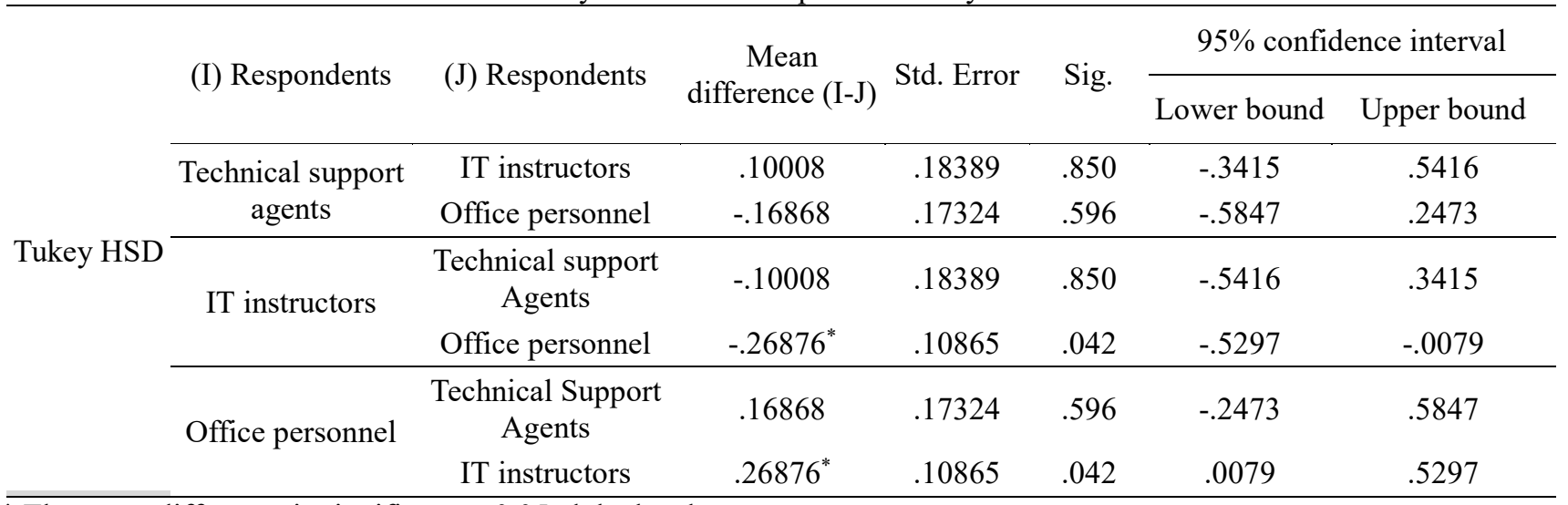

* The mean difference is significant at 0.05 alpha level.

\subsection{Significant Difference in the Evaluation Among}

the Three Groups of Respondents

The result revealed in Table 9 shows that there was a significant difference noted in the evaluations of the respondents, $\mathrm{F}(2,62)=3.164, \mathrm{p}=0.049$. This result implies that the evaluation made by the three groups of respondents significantly differs from one another.

To determine which group evaluation significantly differs from the other, Tukey HSD was used as a post hoc test.

As shown in Table 10, the evaluation made by the IT instructors significantly differs from the evaluation made by the office personnel. Looking back at the previous results, it can be seen that the newly developed system is more acceptable to the office personnel than IT instructors. This result could be attributed to the fact that IT instructors, in general, are more knowledgeable in terms of system development than the office personnel.
3.4 Problems Encountered by the Respondents

The respondents listed all the problems encountered during their testing of the developed multi-channel support and ticketing interface for online support management system platforms. And the most common problems include slow response time, difficulty to navigate in finding necessary features, fonts in the navigation options are small and overcrowded interface. And there should be an email validation checker whether the email domains provided by the requester are valid or not.

The results of the study contribute to the understanding of the impact of multi-channel support and ticketing interface for online support management system platforms design for learning environments. The positive feedback of the respondents aligns with the need for growing evidence on the computerized support for the universities. 
As indicated by respondent's feedback, the system is easy to use, it can cater to the needs of the respondents, and provided useful insight into how the system might be developed and improved to suit the needs and tastes of the students. The online support management system can provide consistency and individualized support to learners in a learning environment because they are involved with students throughout their educational experience with the universities. Online support services can improve the quality of students' academic experiences, connect them to the university, and help them develop the self-directed learning skills that are necessary to succeed in a virtual learning environment and thus empower them to achieve their learning goals. Furthermore, online support services can provide scaffolding for success.

\section{CONCLUSIONS AND RECOMMENDATIONS}

Based on the findings, the following are concluded:

1. The development of the multi-channel support and ticketing interface for online support management system platforms involves the Conceptualization, Technical feasibility, Development, Pilot testing, Creating user's manual, and Evaluation of multichannel support and ticketing interface for online support management system platforms.

2. Technical support agents evaluated the compatibility and usability of the multi-channel support and ticketing interface for online support management system platforms as Highly Acceptable, while the IT instructors found these characteristics of the system as Acceptable and office personnel perceived the functional suitability, usability, and maintainability as Highly Acceptable.

3. There is a significant difference in the perception of the IT instructors, technical support agents \& office personnel on the multi-channel support and ticketing interface for online support management system platforms in the seven (7) specifications based on ISO/IEC 25010 software product quality.

4. Problems encountered during the use of the multichannel support and ticketing interface for online support management system platforms are slow response time, difficulty to navigate in finding necessary features, fonts in the navigations options are small, and over-crowded interface. And there should be an email validation checker whether the email domains provided by the requester are valid or not.

Based on the conclusions of the study, the following are recommended:

1. Based on the overall result obtained by technical support agent, it is recommended that when it comes to performance efficiency and maintainability the system needs improvements to make it more changeable for future modifications for better usage.
And lastly, based on the overall result obtained by the IT instructors, although the mean of the seven (7) criteria used is still equivalent to a verbal interpretation of Acceptable, the developed system needs improvement.

2. For future studies, it is recommended to use an omnichannel support system that will deliver a unified experience across all support channels to help educators and instructional designers better prepare instructional content for online learning. It is also recommended to include an inventory of information technology assets and have an SMS features capability for notifying the requesting end-users because some requester has limited internet connectivity.

\section{ACKNOWLEDGMENT}

This paper has been supported and funded by the University of Antique.

\section{REFERENCES}

Crouch, S. 2019. Developing maintainable software|Software Sustainability Institute. https://www.software.ac.uk/resources/guides/developing -maintainable-software.

European standards, 2011. ISO/IEC 25010 Systems and software engineering — Systems and software Quality Requirements and Evaluation (SQuaRE) - System and software quality models. https://www.enstandard.eu/iso/iec-25010-systems-and-softwareengineering.

Franca, J., Soares, S. 2015. SOAQM: Quality model for SOA applications based on ISO 25010, Proceedings of the 17th International Conference on Enterprise Information Systems, 60-70.

Gallimore, D. 2020. Multi-Channel support. https://www.outsourceaccelerator.com/glossary/multichannel support/.

Goersch, D. 2002. Multi-Channel integration and its implications for retail web sites. ECIS 2002 Proceedings. 11. http://aisel.aisnet.org/ecis2002/11

Haoues, M., Sellami, A., Ben-Abdallah, H., Cheikhi, L. 2017. A guideline for software architecture selection based on ISO 25010 quality related factors. International Journal of System Assurance Engineering and Management, 8 (Suppl.2): S886-S909.

Ismaili, F, Bulku, A., Caushi, B.A. 2018. Analysis, design and implementation of a helpdesk management system Case study "Albanian Radio Television. 2018 41st International Convention on Information and Communication Technology, Electronics and Microelectronics (MIPRO), Opatija, Croatia, 0485-0490, doi: 10.23919/MIPRO.2018.8400092.

Kanellopoulos, Y., Antonellis, P., Antoniou, D., Makris, C., Theodoridis, E., Tjortjis, C., Tsirakis, N. 2010. Code 
quality evaluation methodology using the ISO/IEC 9126 standard. International Journal of Software Engineering \& Applications, 1, 17-36, doi: 10.5121/ijsea.2010.1302.

Lui, W., Piccoli, G. 2016. The effect of a multichannel customer service system on customer service and financial performance. ACM Transactions on Management Information Systems, 7, doi: $10.1145 / 2875444$.

Mission, R. 2020. Online support management system for university of antique, Journal of Innovative Technology Convergence, 2, 39-52

Nielsen, J. 2012. Usability 101: Introduction to usability. Nielsen Norman Group, https://www.nngroup.com/articles/usability-101introduction-to-usability/.

Ozdoruk, C. 2020. Multi-channel-customer-service. https://www.netomi.com/multi-channel-customerservice.

Pan, J. 2019. Software reliability. https://www.users.ece.cmu.edu/ koopman/des_s99/sw_r eliability/.

Papazoglou, M., Traverso, P., Dustdar, S., Leymann, F. 2008. Service-Oriented computing: A research roadmap. International Journal of Cooperative Information System, 17, 223-255.

Peters, E., Aggrey, J. 2020. An ISO 25010 based quality model for ERP systems. Advances in Science, Technology and Engineering Systems Journal, 5, 578583.

Stone, M., Hobbs, M., Khaleeli, M. 2002. Multichannel customer management: The benefits and challenges. Journal of Database Marketing 10, 39-52 DOI: 10.1057/palgrave.jdm.3240093 